\title{
The Limits of Justification: critique, disclosure and reflexivity
}

\author{
Lois McNay
}

\section{Introduction}

One of the defining premises of Frankfurt School critical theory is that, given the situated nature of all thought, emancipatory political critique necessarily has immanent foundations. Critique is politically effective when it is guided not by transcendental principles but by existing values and norms embedded within the practices and struggles of a given age. The task of critique is to identify these endogenous normative resources, reconstructing them in such a way as to establish the evaluative emancipatory perspective from which it diagnoses a particular social order. Although he aligns himself with the Frankfurt school tradition, the critical theory of Rainer Forst is distinctive because it rejects this founding premise of immanence on the grounds that it deprives critique of the independent normative foundations necessary to support truly emancipatory claims. To be universally binding, critique must have the context transcending validity that can only be derived from free-standing principles. Forst finds such autonomous grounds in the principle of justification which he maintains represents the transcendental core of practical reason. Mindful however of the 'metaphysical slumber' that may ensue from this idealising move, Forst also insists, in line with the Frankfurt School approach, that to be genuinely radical, critique must be concerned above all to develop a critical theory of existing injustice and to build into itself the capacity for reflexive selfscrutiny. Power is the 'first question' of justice and normative theory is empty unless accompanied by a disclosing focus on oppressive, dominating and other unwarranted social hierarchies. Attentiveness to power also implies that critique understand itself as a type of 
reflexive practical knowledge that critically evaluates its conceptual limitations and blindspots in response to changing social practices. Justification critique’s inherent capacities for disclosure and reflexive self-scrutiny are indispensable in ensuring its radical trajectory and avoiding the pre-democratic, prescriptive tendencies that Forst finds so problematic in mainstream ideal theorising.

In this paper, I argue that Forst's paradigm is less radical than claimed in so far as it fails to establish an immanent connection between the role of justification as a transcendental principle and as tool of disclosing, reflexive critique. My primary concern is with the feasibility of the critical rather than ideal side of his project and I maintain that the construal of justification as a trans-historical principle, by definition, shields it from systematic criticism and consequently constrains critique’s capacity for reflexive self-scrutiny. In a general sense, reflexivity is ignited by disclosure to the degree that it is reflection on the nonidentical elements of social life, on that which doesn't fit in, that may prompt critical reevaluation of a theory's conceptual framework Justification critique’s capacity for disclosure, and hence reflexivity, is crucially limited, however, by Forst’s reliance on a tendentious concept of noumenal power which does not satisfactorily explain the complex, material dynamics through which major structural inequalities are reproduced. Its normative scope is further stymied by a disregard of the latent power dynamics often at work in the actual conversation about justice that subvert formally equal relations of justification and make it difficult for certain individuals to be taken seriously as democratic interlocutors. In short, the lack of reflexivity is evident in Forst's failure to adequately consider how entrenched asymmetries of power may require him to advance beyond an abstract, onedimensional account of mutually owed justifications. Vacillating inconsequently between 
transcendent and immanent perspectives, I conclude that justification critique is in fact a selfundermining theoretical enterprise

\section{Immanent and transcendent foundations}

Despite considerable divergences in their respective accounts of critical theory, thinkers of the Frankfurt School share one underlying intellectual premise, namely that, given the situated nature of all thought, emancipatory theory should necessarily take the form of immanent social critique. Radical critique is most effective when it is guided not by transcendental moral principles but by values and norms that are already embodied, in an incomplete form, in the core institutions, practices and beliefs that structure social life. The task of critique is to reconstruct these normative resources in such a way as to establish the evaluative perspective on which to base social criticism and make proposals for change. Although critical theorists have differed widely in their approach to the reconstruction of socially embedded norms - arguably the thinkers of the second and third generation being more successful in this reconstructive effort than those of the first - they all can be said to share a common commitment to the tenet of critique's immanent foundations.

What sets the work of Rainer Forst apart from the Frankfurt tradition with which he otherwise strongly identifies is his rejection of the necessary presumption of critique's immanent foundations. He maintains that the grounding of critique in socially internal values deprives it of the impartial perspective from which its evaluative insights may be systematically justified. Lacking external standards, critique is reduced to an unsystematic and parochial relativism where 'we would just replace one form of justification with another 
more to our liking' (Allen, Forst, Haugard 2014: 11). To ensure irrefutable emancipatory force, critique must be based in principles and standards that transcend particular contexts and that, in so far as they are genuinely independent, all subjects can recognise as morally binding. Theorists such as Habermas and Honneth are well aware that their rejection of thought's morally freestanding status has troubling relativist implications and they aim to circumvent this by basing critique in principles that, although immanent, have a generalizable or 'quasi-transcendent' validity by virtue of their social omnipresence. Such principles of intra-mundane transcendence are found in seemingly foundational features of social interaction identified by Habermas as the universal pragmatics of communication and, by Honneth, as the primary role that recognition plays in healthy individuation processes. But, for Forst, these attempts to derive a 'rational universal' from social ontology are either too biased to deliver a sufficiently impartial foundation for critique or too procedurally thin to have binding moral force (Honneth 2004). Against Honneth, Forst maintains that the recognition paradigm lacks impartiality because it erroneously generalises a thick ethical good, qua a substantive anthropology of self -realisation, as the basis for inclusive political structures. As complex and open as a formal theory of the good or flourishing life might be, it will always fail to encompass the plurality of possible ethical ways of life and will unavoidably yoke respect for persons as 'ends in themselves' to 'particular ends or ways of pursuing ends that are supposed to characterise a good life’ (Forst 2007: 118). Forst concludes that a comprehensive theory of social justice can only do justice to the good, 'the less it rests on particular conceptions of the good' (2007: 118.). Although Habermas avoids such a conflation of the just with the good, the difficulty with communicative ethics is that it rests on a justificatory procedure that is too formal to prevent non-democratic outcomes. Forst identifies a 'normative gap between the pragmatically derived and hence weak transcendental 'must' of discourse ethics and the stronger, normatively justified 'must' that 
he holds is crucial for a binding political theory of justice and its essential components, such as a theory of human rights ( 2007: 59).

To avoid the relativism and formalism that hamper the critical theories of his contemporaries, Forst consequently concludes that critique must have autonomous moral grounds and such a 'fundamentum inconcussum' can be established though constructivist reflection on the essential nature of practical reason. If we reconstruct what it means to reason practically, then we discern at the very heart of the process, a shared basic practice of justification. In answering fundamental questions such as 'what should I do?' or 'why did I believe that a certain course of action was permissible or necessary?', the individual is required to 'provide reasons that can justify actions according to criteria that are valid in a moral context' (2007:15). Valid criteria in this sense of moral justification are not subject relative but inter-subjective in nature; the point of justification is not to explain actions as the most rational way of realising personal ends and goals, but rather to provide reasons for actions that others, who are morally affected, cannot reasonably refuse. Practical reason is, at its core, 'the ability to answer a moral question with a morally justifiable answer that can be supported intersubjectively. It is reasonably justified if no moral reasons speak against it ‘(2007: 15) This inter-subjective formulation highlights a further defining feature of reasonable justification that, for a normative claim to be accepted as valid, it must meet the criteria of reciprocity and generality. Reciprocity is defined in terms of content - 'no one may refuse the particular demands of others that one raises for oneself' - and reasons - 'no one may simply assume that others have the same values and interests as oneself or make recourse to 'higher truths' that are not shared' (2007:6). Generality means that reasons for generally valid basic norms must be sharable by all those affected', that is they must not exclude the objections of anyone affected (2007:6). The criteria of general and reciprocal justification generate a binding normative force that is stronger, according to Forst, than 
comparable ideas of de facto accord, like-mindedness or assent that rest on weaker notions of moral reasoning as intersubjective acceptability or agent neutrality. At the same time, by making the regulative principle of deliberation that which cannot be reasonably rejected rather than the demanding notion of consensus, Forst's model overcomes a problem with the Habermasian one, namely it shows us how a claim can be justified even if agreement cannot be achieved. Moreover, by accommodating a degree of disagreement in this way, justification critique is arguably better able to deal with the 'diversity of evaluative approaches' that should characterise truly inclusive deliberation. Forst maintains that the principle of justification is unconditional in so far as it is not dependent on any prior notion of the good or other extraneous social criterion. Moral constructivism reveals justification to be the essence of practical reason; there is no other entity that can be appealed to beyond reason because reason constitutes its own grounds, as he puts it: 'there are no external derivations” that can trump the construction'(2007: 7). This autonomy establishes that 'moral persons have a fundamental right to justification and corresponding unconditional duty to justify morally relevant actions' (2007: 21).

Forst argues that the a-priori of justification establishes incontestable normative foundations for a binding concept of justice: 'moral constructivism form[s] the normative core of political constructivism (2007: 6). Justification is a basic moral right in the sense that all humans have the right not to be subjected to norms and institutions that cannot be adequately justified. The first task of justice is accordingly to guarantee a 'basic structure of justification', that is, one in which all affected subjects have an irrevocable right to collectively deliberate and decide about the institutions that they are to live under and veto any arrangements that cannot be reciprocally and generally justified to her. The basic structure of justification is not intended to provide a complete blue print for a fair society, but 
rather to establish the 'minimally' just conditions and principles upon which further discussion about a 'maximally' just society can be realised. In succeeding discussions about maximal justice, the criteria of general and reciprocal justification provide the independent standards for judging whether particular social arrangements have legitimate foundations or not. The criteria provide a morally rigorous 'normative grammar' that 'works like a filter to sort out justifiable from unjustifiable claims, one that opens up and at the same time restricts the possibility of justice claims’ (2011: 113).

\section{Disclosure and reflexivity}

While the a-priori of justification appears to provide a way out of the relativist dilemmas of immanent critique, it seems, at first glance, that Forst has moved some distance from the type of approach usually understood to typify critical theory. Indeed, a number of commentators hold that his claim that critique 'needs' transcendental foundations pushes the justification paradigm closer towards the style of political reasoning that Bernard Williams famously termed political philosophy as applied ethics (see Allen 2014: 83; Olson 2014: 100). On this view, Forst's attempt to transcendentalize the justification principle replicates the ideological errors of ideal theory where contingent social practices are reified as freefloating universal norms (e.g. Tully 2011). Forst emphatically rejects such comparisons with ideal theory arguing that justification critique offers a far more radical approach to justice because of its inherent capacity for disclosure and reflexivity. With this claim, Forst explicitly re-connects justification critique to Frankfurt School critical theory and its premise of the inescapable dialectic of power and reason. The dialectic implies, inter alia, that to be politically effective, thought about emancipation must proceed through a critical theory that exposes existing injustice and domination. Accordingly, Forst states that power must be the 
‘first question' of justice and 'a critical theory of (in)justice has to be above all a critique of the existing relations of justification' (2011: 120). It is not that ideal theorists are uninterested in how moral principles might bear on unwarranted social hierarchies, but for them, this is an extrinsic and derivative matter of 'application' whereas, for Forst, the critique of power lies at the very heart of normative reasoning. Emancipatory political thought is most effective when it disrupts settled norms and assumptions through the unmasking of injustices: 'every theory of justice requires a complex theory of injustice, not just as a normative account, but also in the form of a social analysis' (Forst 2011: 114). Justification critique enacts its disclosing function not only through radical social criticism but also through its recursive structure. What Forst finds particularly troubling about ideal theory are the 'pre-democratic', prescriptive tendencies that flow from its method of antecedent justification. This has the effect, albeit unintended, of undermining democratic sovereignty by rendering it an organ for executing pre-given moral principles rather than treating it as the autonomous political body that actively determines the content of a just social structure (2007: 106- 10). Forst circumvents the problematic imposition of 'teleological values' because his constructivist method is 'discursive' rather than 'metaphysical' meaning that, other than 'a certain conception of the person and particular criteria of reasonable practical justification', everything else is determined by the discursive practice itself (2007: 111). Discursive thinness permits genuine democratic self-determination in the public use of reason because it is not the political philosopher but citizens themselves who autonomously determine the normative content of justice and revise it when appropriate (2011: 8). Contra Rawls, the conversation about justice can never be finished; if it is to retain emancipatory relevance it must be ceaselessly taken up and given renewed meaning by each successive generation and constituency to whom it pertains. The radical bite of justification critique emanates therefore from the way it positions individuals as co-authors of the fundamental norms that guide 
society, replacing passive, 'principle interpreting' accounts of justice with an emancipatory 'principle-generating' account (2007: 184). Combined with the critique of power, its recursive structure enhances democratic inclusivity by eschewing normalising constructions of 'reasonable' deliberators and opening itself to voices from below, in particular, those of disempowered and marginalised groups, permitting them to challenge the status quo and to dispute settled notions of justice, affectedness and subjection (2014b:178).

The dialectic of reason and power also demands that critique build into itself a heightened capacity for reflexive self- scrutiny in order to guard against theoretical bias and conceptual reification. Critical theory has always understood itself as a highly self- reflexive form of evaluative thought that necessarily builds into itself a capacity to test and revise its values and principles in the light of what political practice might reveal about their emancipatory relevance. Forst endorses this by taking up Kant's well known notion of the 'critique of critique', that no aspect of social practice should be immune from critical scrutiny, including critique itself. Immanent grounds may be normatively insufficient for emancipatory critique but it is just as unsatisfactory to resort to notions of 'otherworldly transcendence' to fill this foundational gap. This would be to fall into a 'metaphysical slumber' which neglects thought's own social preconditions: 'no social critic, no matter how radical, is not also an immanent critic' (Forst 2011). A theory can only count as critical and radical, in Forst's eyes, in the extent to which it understands itself as 'an activity that reflects back on itself and its own blind spots and exclusions in a self-critical manner (2011: 8).

It is in relation to the issue of reflexivity, however, that Forst's assertion that justification is simultaneously a principle of transcendence and immanence, of autonomy and critique, becomes perplexing. Put bluntly, how exhaustive can critique’s reflection upon its own presumptions, blind-spots and potential exclusions be if its animating core supposedly 
floats free of particular configurations of power? If the principle of justification is a universal constant, then, by definition, there must be a limit to the extent to which it is open to critical evaluation and rethinking should it be found to be less inclusive than it initially seems. By removing the justificatory essence of critique from the hermeneutic circle, Forst appears to drastically curtail the scope of the supposedly 'indispensable' tenet of the 'critique of critique'. The reflexive capacity of critique is not unrelated to its disclosing function for it is the unmasking of suppressed, negative aspects of social experience that frequently serves as the catalyst for critical self -scrutiny. Reflexivity entails not just acknowledgement of alterity and non-identity but the capacity to respond as fully as possible to the potentially destabilising implications that this other perspective may have for one's previously settled view of the world (e.g. Bohman 2008). But, if reflexive examination is prompted in part by a theory's ability to disclose and engage with the non-identical elements of social life - as Adorno puts it, the 'cross-grained, opaque, unassimilated material' - then justification critique is further undermined because of Forst's reliance on a tendentious account of power as a noumenal force (Adorno 1974: 151). Its central premise that social relations are secured through justificatory narratives that rest on the 'acceptance of reasons' forecloses an adequate understanding of the materiality of power and the complex, often indirect ways in which inequality and oppression are perpetuated. As I argue in the following sections, the inadequacies of Forst's account of power, qua disclosing critique, foreshadow an inability to advance beyond an empty formalism when thinking about how, in the conversation about justice, deep discrepancies of power between democratic interlocutors might be mitigated.

\section{Noumenal power}


Forst claims that in order to understand power, it is necessary to understand justification and accordingly proposes that social relations are conceptualised as relations of justification (Forst 2015). By conceptualising society as multiple, overlapping orders of justification, the task of radical critique is to examine the legitimacy of existing justifications for social hierarchies and to expose the lack of justificatory practice in other settled and seemingly inevitable areas of social practice. The overall aim is an exhaustive analysis of 'all those more or less institutionalized social relations and structures which .. are marked by forms of exclusion, by privileges and domination’ (2011: 8). The correlate of Forst's linguistic construal of sociality is the idea that power is essentially a noumenal, discursive, cognitive or intellectual force - he uses the terms interchangeably - that operates through control over the 'space of reasons' (2011: 9). Power is the capacity of some individuals to get others to think or do something they would otherwise not have thought or done, it is the ability to: 'determine the limits of what can be said and thought and.. of what is accepted and acceptable, of what is justified' (2011: 103). Power is emphatically not a matter of strength or will, nor a material state of affairs, but one of convictions and beliefs : 'to be a subject of power is to be moved by reasons that others have given me and that motivate me to think or act in a certain way intended by the reason giver (2014a: 2). This cognitivist construal does not mean that the reasons given for a particular state of affairs need be fully justified and coherent, they may be false or misleading and used to justify relations of oppression, subordination and inequality. But, in essence, even in cases of extreme social disparity, power always acts upon 'cognitively motivated subjects' and rests on the recognition and ‘acceptance of reasons’ (2014a: 9).

If 'power is what goes on in the head', then an issue that immediately confronts Forst's rarefied conception is how to explain types of power whose impact is more 
immediately 'material', whose modus operandi is not primarily the manipulation of consciousness and the acceptance of reasons but the shaping of the socio-structural and practical conditions of existence. Such types of material power not only follow very different logics but arguably are prior to and constitutive of noumenal forms in so far as they create the underlying social conditions in which specific reasons and justifications only become intelligible in the first place. Material power can be conceptualised in a number of ways, including, notably those ideas of disciplinary embodiment, theorised by Foucault, Bourdieu and others, which provide a powerful explanation, inter alia, of the persistence of inequalities of race, gender and class in formally equal democracies. On these accounts, inequalities endure not so much because individuals buy into justifications (good or bad) about their conventional social role but rather because objective asymmetries of power are internalised in the body as a cluster of naturalised subjective dispositions (habitus). In terms of gender, the practical living through of normalising bodily tendencies reproduces wider social inequalities and renders women (and men) unconsciously complicit with their own subordination. Thus, at a rational level, individuals may be conscious of the shortcomings of conventional hierarchies of gender but, at the level of emotional and psycho-sexual dispositions, they may be deeply invested in their continuing subjection in the sense captured by Butler's notion of 'passionate attachments' (Butler 1997). This kind of embodied power appears to have little to do with justification precisely because it operates beneath the radar of reason through the shaping of corporeal being in accordance with the tendencies of the world.

Forst insists, however, that ideas of disciplinary bio-power do not seriously challenge his concept because, ultimately, to be efficacious all types of power necessarily possess a noumenal essence: 'material means...only serve their function if they are seen as reason giving' (2014b:180-1). Thus, the material power of money can only be properly explained, 
according to Forst, with reference to its noumenal effects for 'money only motivates those who see its use as justified and who have aims which make money necessary’ (2014b: 1801). If people do not recognise the justification for money, then it ceases to have power over people. This seems questionable, however, if we think about how the lack of money, in the form of maldistribution of material resources, imposes brute constraints on the life chances of individuals regardless of whether they recognise its use as ‘justified’ or not. Analogously, hegemonic gender norms would not cease to have an influence on women if they chose not to recognise the patriarchal arguments conventionally used to justify them. Nonetheless, Forst maintains that a Foucauldian notion of disciplinary embodiment that bypasses reason represents a ‘super -Cartesian' separation of the symbolic realm from the material one with the untenable implication that there is a corporeal reality 'beyond justification’ (2014a: 13).

The disclosing potential of a notion of power that turns around the acceptance of reasons is further compromised if we consider another way of thinking about the materiality of power, namely the systemic mechanisms that maintain structural inequalities. Take the case of gender, most feminists concur that women's subordination in advanced democracies no longer relies, in any significant sense, on patriarchal justifications (although they undoubtedly exist), but rather on entrenched systemic dynamics that disadvantage women regardless of whether they accept conventional norms or not. Susan Okin famously described this impersonal mode of subordination as 'a cycle of socially caused and distinctly asymmetric vulnerability by marriage' denoting the combined effects of a skewed domestic division of labour, especially as it relates to child rearing, interacting with the operations of a gender segregated labour market (Okin 1989: 4). This impersonal cycle has an effect on all women, even those who are unmarried and childless rendering them 'vulnerable to 
subordination and deprivation in most societies in the world (Young 2009: 228). Forst concedes that such 'subjectless' modes of oppression present a challenge to his cognitivist notion to the extent that they appear to function on another level entirely to that of the acceptance of reasons. He insists nonetheless that social structures do still depend upon noumenal power but that, in this impersonal form, it takes hold of individuals through the mechanism of narrative inculcation rather than that of interpersonal influence. Moreover, noumenal power in this structural sense is defined very broadly including not just direct appeals to reason but unconscious socialisation processes, false narratives, ideological distortions, emotional investments and so on. On his account, imperfect social structures are often accepted because it is felt that nothing else is available; acquiescence is generated by naturalising narratives that make a particular order seem inevitable and thereby socialise individuals into a conformist 'frame of mind' (2014a:10). Gender inequality persists because, although the person of the patriarch may no longer be present in western democracies, patriarchal narratives continue to exert an enduring influence over women who conform to its rules for 'reasons of love, admiration, self- interest, convention, religious upbringing, fear, or despair '(2014a: 16).

Sexist rationales may well be socially entrenched but Forst's suggestion that women's subordination persists primarily because of the widespread acceptance of patriarchal narratives rather than because of structurally generated gendered vulnerabilities is not convincing. Women's subordination has little to do with the acceptance of false narratives or ill-informed choices so much as a structural lack of opportunities. Poor women, for instance are frequently placed in situations where they have few options and where these options may be organised to provide few gains, often even to be "no win”. In such situations, the only rational course is often for women to accept low-paid domestic and sex-work as well as 
unpaid responsibilities (e.g. Jaggar 2014: 34). Likewise there is considerable sociological evidence to suggest that nowadays, many women and men do not unthinkingly buy into traditional ‘narratives’ of gender; they see marriage and parenting in terms of a shared partnership rather than fixed roles and have expectations of equal treatment in education and work. Yet, despite these expectations, gender inequality persists suggesting that a convincing explanation lies not in the enduring noumenal force of patriarchal narratives but rather in structural dynamics that have a determining effect regardless of individual beliefs. The persistence of labour markets that disadvantage women combined with lack of state attention to domestic work and child care mean that even less conventional, egalitarian minded couples are often compelled to adopt a traditional gender division of labour against their best intentions. It makes sense to choose to develop the husband's professional skills rather than the wife's because, in most cases, this ensures greater economic security (Young 2009: 228). In short, it is not evident that inequalities of gender persist primarily because of justificatory narratives but rather because of systemic dynamics that auto-poetically reproduce them. As Amy Allen puts it 'systemic relations of dominance and subordination....are probably always connected to.. hegemonic narratives of justification- but this does not mean that they are inculcated in individuals through or by means of... such justifications or even that they are recognized by their targets as reasons to act in a certain way (Allen, Forst, Haugaard 2014: 18-19).

In sum, Forst's assertion that it is only when we understand justification that we understand power is doubtful. The orientation of social critique around a logic of justification in fact initiates a discursive reduction upwards where relations of power that do not operate according to a one-dimensional linguistic rationale are occluded. ${ }^{i}$ At points, Forst attempts to mitigate this symbolic occlusion by stating that justificatory power does not work only 
through the recognition of reasons but encompasses broader non-cognitive socialising dynamics. This gesture is unsupported however by further conceptual elaboration and the concept of power becomes overly diffuse and emptied of diagnostic bite. At other points, Forst retreats from this capacious stance insisting on a narrow essentialist definition where : 'to be a subject of power is to be moved by reasons that others have given me and that motivate me to think or act in a certain way intended by the reason-giver' (Forst 2014a ). This hyper-rationalist notion is critically limited when it comes to explaining complex dynamics of embodiment, structural causation and other material forces. Forst's vacillation between inclusive and restricted concepts remains unresolved and forestalls the development of the differentiated, multi-dimensional account of power necessary for effective social critique. As I discuss in the next section, the limited disclosing capacity of Forst's concept of power is symptomatic of a more general shortcoming in his thought, namely the failure to integrate transcendent and immanent perspectives in such a way as to engender a form of radical, self-reflexive critique.

\section{Justification and justice}

The radical bite of justification critique is ensured not just by a critical theory of injustice but also by the recursive structure that, in principle, renders it sensitive to the perspectives of those citizens not normally included in the conversation about justice. The justification principle has an explicitly maieutic function intended to bring to the fore unnoticed forms of social suffering and injustice (Cavell 1990: 108). It is, according to Forst, ignited by 'the claims of individuals themselves' and bestows paramount importance on 'their concrete experiences of...political powerlessness and social exclusion' (2007: 121). It is one 
thing, however, to assert an equal right to justification in an abstract recursive sense and another to ensure that equality will be realised in practice in the actual conversation about justice. It may well be that, in the idealized space of practical reason, where subjects are disembodied justificatory agents, they do indeed understand themselves as 'reasonable, autonomous and moral beings who must be able to account for their actions to one another' (2007: 22). But, in the situated deliberative encounter, individuals frequently fail to treat each other as reasonable and morally autonomous beings. Latent dynamics of power and authority may subvert formally equal relations making it far more difficult for certain individuals and groups to be taken seriously as justificatory agents than others. As Miranda Fricker (2009) reminds us, 'testimonial injustice' disproportionately effects subordinate groups who are often subtly stigmatised and de-legitimated as speakers, their speech frequently discounted, trivialised or ignored. History provides numerous examples of politically marginal and oppositional groups (suffragettes, civil rights activists, environmental campaigners) who, as a result of such processes of symbolic de-authorisation, have had to resort eventually to coercive forms of civil action to be taken seriously as democratic interlocutors (e.g. Medearis 2004; Stears 2010).

This problem of the gap between formal and actual justificatory equality is potentially acute for Forst given the transcendental grounds of his theory. What he deems to be the universal practice of justification may turn out to be a contingent socio-cultural practice that is less inclusive then he presumes. The hegemonic imposition that flows from this discursive universalism takes effect not through the direct prescription of Western ideals but through the insidious naturalisation of the linguistic and epistemic habits of dominant classes. In a cross cultural context, for instance, the idea of reasonable justification may reflect the depersonalised sensibility and linguistic habitus of Western elites which are, if not wholly 
inaccessible to less privileged, non-Western groups may nonetheless be deeply estranging and hence tacitly exclusionary. Such occluded status quo bias is a difficulty frequently associated with Habermas's communicative ethics largely because of its attempt to stringently confine speech acts to their supposedly rational core. A consequence of this delimitation is that disempowered groups may find that their experiences of injustice are de facto excluded from consideration in discourse ethics. Certain experiences of oppression and disempowerment are by their very nature confusing, inchoate or fragmenting and hence are inherently difficult to reconstruct in the rational terms that Habermasian validation requires (e.g. Honneth 2007). Forst claims to circumvent such status quo bias by invoking the thinness of his discursive constructivism which, unlike the Habermasian rationale, does not impose conditions of any kind upon the manner or content of the justificatory process. The definition of what counts as 'reasonable' justification is left entirely open and must be determined by participants in debate according to the demands of their specific context: 'only reason - constantly reflecting on what counts as reasonable and whether that is deserved can provide a solution here' (Allen, Forst, Haugaard 2014: 21). The parsimony of justificatory monism creates the space for 'evaluative pluralism' and consequently for disempowered and marginal groups to be heard and thus enables Forst to rebut criticisms of ethnocentrism and other types of status quo bias. Indeed he makes the counter-charge that it is, in fact, those who level such criticisms who are guilty of ethnocentrism because they reify cultural difference as an insuperable barrier to understanding and thereby deny the 'other's' capacity for justification: ' [they] homogenize non-Western societies as frameworks in which no radical critique asking for new or better reasons was either possible or legitimate' (Allen, Forst, Haugaard 2014: 21). It is imperative, in Forst's view, to cut through the superficial appearance of unbridgeable difference in the cross cultural encounter in order to discern the 
basic demand for justification that always underlies political claims no matter how seemingly diverse.

Yet although Forst upholds the sensitivity of justification critique to context, that it takes account of the 'normative reality’ of political demands emanating from disempowered groups, it is hard to see how, in practice, he makes good on such claims. If the abstract right to justification is to be truly inclusive then it behoves Forst to address the precise nature of its internal connection to situated forms of rationality and speech. But the theory rarely moves beyond the assertion of a speculative justificatory equality to consider seriously what participatory parity requires given entrenched asymmetries of power between democratic interlocutors. For example, permitting citizens themselves to define the nature of the justificatory process is not really a satisfactory solution to status quo bias because it simply displaces the problem unaddressed from the hypothetical scenario to that of the actual conversation. No indication is given as to what concrete safeguards might be put in place in the actual scenario to prevent powerful citizens from defining reasonable justification in a way that continues to favour their interests over those of the less powerful. In any case, the justificatory process is not necessarily as open as Forst presumes in so far as the 'criteria' of general and reciprocal acceptability potentially pose considerable barriers to the inclusion of marginal and oppressed voices. Although it supposedly ignites the justificatory scenario, the testimony of oppressed groups can only be fully vindicated by passing the threshold of general and reciprocal acceptability to all participants in the conversation: ‘ experiences of disrespect and exclusion need to be transformed into generally and reciprocally justifiable claims to legal, political or social respect and inclusion’ (Forst 1999: 157-8) Given that, by virtue of their intrinsic negativity, many experiences of injustice, are marked by 'structured heterogeneities and discontinuities', it is not clear how this transformation into homogenous 
and generally acceptable justificatory claims is supposed to occur (Mills 1998: 28 ). It may be uncontentious in the frictionless, symmetrical world of the ideal conversation, to claim that all perspectives, those of privileged and suffering interlocutors alike, be redeemed in such a standardized manner. In the actual situation of polemical and unequal debate, however, it is unlikely that many deep injustices could in fact pass such an unchanging justificatory threshold. One only has to think of the contentious nature of contemporary discussions over migrant rights to see that even cases of intense humanitarian concern, that seem to possess a prima facie justifiability in Forstian terms, are often far from commanding general and reciprocal assent.

Forst tries to smooth over this discrepancy between ideal and actual scenarios of justification through the circular argument that real world situations of injustice must always be answered through the counterfactual thought experiment that, under ideal epistemic conditions, democratic citizens would not find them justifiable. For example, he maintains that, on his definition of justification, it would not be possible for gay individuals to be denied an equal right to marriage because this would involve relying on 'thick' religious and traditional notions of the meaning of marriage that are deeply contested and therefore reciprocally non-generalisable (2011: 113) . But, this seems to overlook the fact that, beyond the hypothetical scenario of justification, the right to marriage for gays continues to be highly disputed on precisely these terms even where it has been legally recognised by the state. Moreover, in pre-determining the outcome of the justificatory process in this way, Forst seems to tacitly draw on substantive, but unarticulated principles of equality, freedom, tolerance, solidarity and so on, in a manner that he explicitly rejects in his criticism of the pre-democratic nature of antecedent justification. In short, he appears to want to have his cake and eat it too; asserting, on the one hand, that the conversation about justice is always 
situated, that there can never by a perspective outside of it, but, repeatedly affirming, on the other, the moral priority of an ideal perspective over a situated one.

Differently put, the justification paradigm fails to reflexively enact the dialectic of transcendence and immanence that Forst regards as a vital element of emancipatory critique. If it turns out that the criteria of general and reciprocal acceptability do disadvantage disempowered interlocutors in the conversation about justice then, on his own definition of reflexivity, it follows that Forst should think more carefully about how to amend the formal process of justification. But this self- reflection is foreclosed by Forst's prioritisation of the abstract procedure of justification over the situated encounter. For instance, issues of interpretative incommensurability and testimonial injustice are bypassed by reliance on an undifferentiated notion of affectability which holds that "in moral contexts the community of justification may not be arbitrarily restricted, but rather must include all those affected by actions or norms in morally relevant ways” (2007: 214). The unqualified term moral relevance does not distinguish adequately, however, between the deep discrepancies that may exist between individuals in terms of 'intensity of affectability' where a given state of affairs may have a far more prolonged and harmful impact upon some individuals than on others. Individuals who have suffered directly from chronic or severe injustice may justifiably feel that a greater urgency and moral weight attaches itself to their view than to those of citizens less directly affected and that this should somehow be acknowledged in deliberation. From this perspective, Forst's stipulation that all groups, regardless of experiential discrepancies, meet the unchanging threshold of justificatory acceptability may constitute a supervening form of epistemic or hermeneutical injustice that compounds the original injustice. In short, the practical enactment of concern for others might require us on occasions to consider whether, with certain types of injustice, it is in fact appropriate to insist on reciprocally 
acceptable justifiability: 'affectability brings with it an excess over rational justifiability’(Fritsch 2015: 813). This is the view of Adorno, for instance, who is sceptical about the possibility of establishing discursive foundations for morality because he believes that our moral responses rest largely on immediate, intuitive reactions to suffering. It is an 'outrage', in his view, to demand that we justify our response to the evil of Auschwitz when it is our spontaneous reactions to the event that should be our normative guide. We instinctively recognise oppression when we see it and grounding morality in a-priori theories and principles is neither desirable or necessary since it entangles us in an infinite chain of argument (Freyenhagen 2013: 198-9). Adorno famously prefers a negativist construal of morality, namely that our normative responses to possible injustices should be directed not by comprehensive principles of the good or the right but by concrete knowledge of social suffering and other 'bads' and what might be done practically to overcome them.

It is not necessary to endorse an epistemic negativism akin to Adorno’s to recognise that in some cases there may be a profound disconnection between the lived reality of suffering, on the one side, and the demand, on the other, that such experiences be vindicated according to pre-given criteria, no matter how seemingly thin. The paradox of equal treatment for all is that sometimes the perspective of what is equally good for all be abandoned temporarily for the sake of its other perspective, that of singular-oriented treatment (e.g. Fritsch 2015: 810). In principle, Forst recognises the significance of this dilemma when, for instance, he invokes Levinas’s claim that moral law derives its authority from 'the face' or singular presence of the other. Yet, concerted exploration of how normative receptivity to the vulnerable subject of injustice may be practically enacted is curtailed by Forst's categorical assertion that empathy generates amoral results. In a circular fashion, he concludes that if there is a role for empathy in the encounter with vulnerable 
others, it can only be the 'reasonable empathy' generated by the criterion of justification (2014b: 176-77).

By cleaving to the unyielding formalism of mutually owed justifications, Forst is in danger of doing what he explicitly denies, namely, treating 'injustice as a 'surprising abnormality' from the norm of justice (Sklar 1990: 17). If a theory of normative validity is to provide a viable internal point of justification for oppressed groups then it must be more responsive than Forst's formal paradigm to the effects of social position on epistemic and linguistic capacity. This need not entail abandonment of the principle of justification so much as the development of notions with greater contextual sensitivity oriented not necessarily towards achieving universally acceptable validation but towards what Azamova (2012) calls 'giving reasons for having reasons'. Justification, on this alternative account, would be grounded in personal experience and the narration of how one has come to one's view and reasons that prompted one to form it. Instead of imposing a normative threshold of acceptability, it would allow oppressed subjects to explain their experiences in their own terms and thereby hopefully generate enhanced understanding of their normative stance as well as shedding light on connections and commonalities with the position of others. Alternatively, responsibility to others might demand a recalibration of the burden of the conversation about justice so that it falls more heavily on privileged than vulnerable interlocutors. Instead of focusing one-sidedly on the formal vindication of the latter's experience and, consequently, tacitly limiting how they can appear to others, it may be more equalising to require the former to cultivate an ethos of 'epistemic responsibility' for others (Fricker 2009). This would involve combatting the inherited cognitive and discursive habits that sustain the hermeneutically marginalising effects of the supposedly impartial perspective. The cultivation of such a sensibility would of course not be easy in the face of the deeply 
entrenched linguistic habitus of privilege but might involve such measures as, inter alia, renunciation of fixed principles of interpretation, willingness to render oneself vulnerable to others, embracing rather than smoothing over experiential disruption and complexity and the use of imagination and sympathy in interactions with others rather than fixed categorisations (Medina 2012: 112ff). In short, challenging epistemic 'meta-blindness' and 'metainsensitivity' to injustice and oppression might require the development of communicative and interpretative virtues quite different to the standardised norms implied in Forst's justificatory process.

\section{Conclusion: reconciliation or vacillation?}

It is difficult to demur from a hypothetical principle that accords the right to justification to all affected but, on closer inspection, it seems to be such a socially weightless notion that its precise relevance to the correction of actual injustices is unclear. At best, the syntax of justification is what Nancy Fraser terms a 'circuitous route' to dealing with unwarranted disparities of power between individuals that may be more effectively dealt with by a direct focus on the nature of the specific injustice in question (see Fraser 2008). Forst's inability to advance beyond a one-dimensional formulation of justification speaks to the contradictory nature of his enterprise where instead of establishing an immanent connection between critical and ideal perspectives, he vacillates inconsequently between the two in a manner that is ultimately self- undermining. No sooner does he establish the universal status of justification as the core of practical reason, then he appears to back track from this by stating repeatedly that there can be no truly objective perspective, that all reasoning is situated and perspectival. But when faced with challenges from the perspective of social 
practice, he prioritises the a-priori of justification over a contextually embedded response. The undermining effects of this vacillation permeate Forst's work and are evident, for example, in the uncertain status of the criteria of reciprocity and generality. Neither first order moral principles or socially derived norms, they lack determinate content and are unsatisfactory from both ideal and critical stances. Hence, for the ideal theorist concerned with grounding justice in independent foundations, the criteria are insufficient because they are not substantive moral principles. As we have seen, this thinness is a deliberate strategy on Forst's part because he wishes to avoid making metaphysical claims and replicating the 'pre-democratic' error of ideal theory. Any normative content the criteria possess must necessarily come to them from the outside, from the deliberations of citizens in a given justificatory scenario. But this thinness inevitably weakens the unconditional moral force that Forst wishes to confer on justification critique. Consequently the criteria are vulnerable to such criticisms from ideal theorists as they are tautologous (generality implies reciprocity), too vague, (a more precise idea of all affected principle needs to be worked out), or require supplementing with other criteria (such as that of priority), to render them normatively effective (e.g. Caney 2014; Muller 2013). To pre-empt such criticisms, Forst implicitly draws on thick norms of tolerance, solidarity, freedom and so on, to demonstrate the criteria's supposed moral rigour. However, as we have seen, this violates the premise that it is citizens who are the rightful authors of democratic principles, not the theorist.

Equally, however, for the critical theorist concerned with immanent social critique, the criteria are just as empty but in the different sense of being abstractions that repress awareness of their social conditions of possibility. According to Honneth, for instance, the criteria would be devoid of normative bite if they did not implicitly presuppose that 'social norms and corresponding roles already exist and determine the elements of justification' 
(Honneth 2011:416). In his view, Forst is only able to establish justification as the universal core of practical reason by fictitiously bracketing off the social context in which dialogue always takes place and which gives it substantive content. Context does not simply constitute the post-hoc setting to transcendental practice but rather is its necessary pre-condition. It is only ever in a given social context that the criteria of justification make sense, for in considering whether particular social relations are just or not, individuals invariably encounter each other as situated beings who draw on their accumulated knowledge of social roles, norms and practices to make such judgments.

In the end, this vacillation between critical and ideal perspectives throws into question where exactly the supposed moral and analytical rigour of the justification paradigm actually lies. But, above all, Forst's methodological indecision undermines the very capacity for reflexive self-scrutiny that he regards as an indispensable feature of emancipatory critique, preventing its lapse into metaphysical slumber, on the one side, and parochial relativism, on the other. The effect of according justification a transcendental status is to immunize it against systematic critical scrutiny since an invariant principle, eo ipso, cannot be subject to extensive revision. There are several grounds, however, on which we might want to subject the justification principle to precisely such critical scrutiny particularly when it comes to questioning its foundational status as the invariant essence of practical reason. From a historical perspective, for instance, Forst's uniform, de-historicised interpretation of all political struggles, regardless of context, as expressions of the self-same demand for the right to justification is dubious. As Jeffrey Flynn argues, for instance, when Muslim women around the world struggle against patriarchy in Islam, they may be asking for equal treatment as Muslims on the basis of a certain interpretation of their rights and duties in the Qur'an but whether this can be construed in the strong terms as a claim about their moral right to 
justification is moot: 'It does not seem to be the case that whenever people demand reasons from others or even when they demand that they no longer be ignored, that they necessarily enter into a kind of dynamic that implicates a moral right to justification (Flynn 2015: 801) It is possible to partially agree with Forst that what distinguishes certain struggles as political is some kind of universal claim, but it remains questionable whether this is most appropriately conceptualized as an assertion of the right to justification rather than, in the more politically germane terms, as an assertion of the right to equality or freedom as Ranciere (1999) and Honneth (2014) respectively hold.

Even on the constructivist scenario set out by Forst, it is doubtful whether justification emerges as the fundamental characteristic of practical reasoning rather than some other intersubjective dynamic principle of, say, dialogue, or recognition. After all, the reason that the need to justify one's position arises in the first place is as a response to the demand emanating from an 'other' who has already been recognized as a partner in dialogue. If reason was not already presumed to be dialogical there would be no duty to justify oneself in a general, reciprocally acceptable fashion. Forst asserts the inter-subjective nature of reason but fails to pursue the potentially de-stabilising implications that this presumption has for the supposedly foundational status of the justification principle. If it is dialogue with the other that precedes and creates the demand for justification, then, as Honneth points out, recognition must be the more fundamental principle: 'mutual recognition always precedes discourse, and the mutual ascription of normative capacities...always precedes justification’ (Honneth 2011: 416). Indeed, according to Honneth, the antecedence of recognition emerges 'unnoticed' in Forst's work - in for instance the idea of 'contexts' of justification - and does a lot of unacknowledged work to make the idea of justification operable. Likewise, Muller 
concludes from Forst's presumption of the intersubjective nature of practical reason that there is a 'deeper root of justice' and more fundamental right than that of justification, namely, the right to participate in dialogue. It is only in the context of a right to participate in dialogue that a subsequent right to justification makes sense: 'dialogue does not take place because there is a need of justification, but the other way round, there is a need of justification because reason is, in its own dynamic and inner life, dialogical' (Muller 2013: 1057). This is not necessarily to endorse the argument that recognition is in fact the more fundamental principle but rather to draw attention to the way in which the conferral of a transcendental status on justification prevents Forst from effectively implementing the type of reflexive selfscrutiny that he regards as essential to emancipatory critique.

In the end, Forst's vacillation is perhaps inevitable in so far as his goals of establishing independent moral grounds for critique, on the one side, and of developing a penetrating critical theory of injustice, on the other, have greater contradictory entailments for political reasoning than he is prepared to acknowledge. In so far as they cannot be reconciled, they represent what Adorno calls torn halves which, when brought together, do not add up to a unified whole (Adorno 1974: 123). A solution to Forst's difficulties, given his stated allegiance to Frankfurt school critique, would be to let go of the transcendental side of his project and construe the right to justification as a contingent historical achievement albeit one that is akin to what other critical theorists term an immanent universal. Historicising justification in this manner would enhance reflexive elaboration of the concept although it would undoubtedly mean giving up on a certain type of strong universalism. But, contra Forst, it doesn't follow that, by de-transcendentalising its governing principle, critique loses the capacity for systematic social criticism and generalizable normative relevance. Indeed, perhaps the real underlying difficulty with Forst's work is the misleading presumption that 
animates it, namely, that if critique cannot find incontestable foundations and a way out of the hermeneutic circle, it must inevitably fall prey to a parochial relativism. This false antithesis between transcendence and immanence forecloses exploration of the complicated middle ground where there are better and worse interpretations of the world and a variety of methodological indices, standards of evidence and conceptual logics with which to test any given theory's respective explanatory and normative merits. Accepting the inescapably situated nature of critique would mean, however, that the validity of its diagnoses and proposals will always be a matter for argumentation and that the critic must be prepared to justify her critical insights without resort to a transcendental guarantee. Critique must be 'guided by a concern for an answer that is right in a context transcending sense and that proceeds in a historicist, comparative, open-ended, and concrete way' (Cooke 2006:70). The attempt to de-historicize the justification principle forecloses what many would regard as the essential strength of an effective critical theory, namely, a dialogical, contextually sensitive, and cumulative style of political reasoning. Moreover, Forst is arguably misguided in thinking that constructivist 'moral invention' can provide a definitive frame for matters of social justice because, as Michael Walzer reminds us, there are always an infinite number of possible ‘inventions’ and because every invention requires interpretation (1987: 26).

\section{Acknowledgements}

I would like to thank the anonymous reviewers of this article for their helpful comments.

\section{Declaration of conflicting interests}

The author declared no potential conflicts of interest with respect to the research, authorship and/or publication of this article 


\section{Notes}

i This occlusion is evident in the way in which Forst treats the issue of violence which, by being conceptually disconnected from that of power, limits an understanding of the structural causes of certain dysfunctional social phenomena. Take for instance the problem of domestic violence endemic to intimate heterosexual relations in all societies, traditional or democratic. Noumenal power provides few conceptual resources for understanding its persistence because the rationale of justification imposes a conceptual hiatus between the phenomenon and the general context of masculine domination. Following Arendt, Forst maintains that violence is the opposite of power because the agency of the victim, qua the capacity to accept reasons, is negated by the perpetrator of violence: the free subject becomes a mere object. The erasure of agency is of course an undeniable effect of violence but this does little to develop understanding of how, in a domestic context, violence does not so much represent the end of patriarchal power but rather one of its symptoms. It is truistic to say with Forst that domestic violence is beyond the scope of reasonable justification for this does not explain why it arises, how it might be a pathological expression of other asymmetrical social dynamics and what might be done to prevent it. Given that it is a pervasive feature of intimate relations, male violence must be connected to the larger societal context of masculine 'scripts' of entitlement, aggression and independence, on the one side and female passivity and feminine scripts of dependence, sacrifice and duty to care, on the other (Hirschmann 2002: 128)..

\section{References}

Adorno, T. (1974) Minima Moralia: Reflections on a Damaged Life. London: Verso.

Allen, Amy (2014) 'The power of justification' in Forst, R Justice, Democracy and the Right to Justification: Rainer Forst in Dialogue. London: Bloomsbury.

Allen, Amy, Forst, Rainer and Haugaard, Mark (2014) 'Power and Reason, Justice and Domination: A Conversation’. Journal of Political Power, 7 (1), 7-33.

Azamova, Albena (2012) The Scandal of Reason : A Critical Theory of Political Judgement New York: Columbia University Press.

Bohman, James (2008) 'Critical Theory as Practical Knowledge: Participants, Observers and Critics' in S. Turner and P. Roth (eds) The Blackwell Guide to the Philosophy of the Social Sciences. Oxford: Wiley-Blackwell.

Butler, Judith (1997) The Psychic Life of Power. Stanford: Stanford University Press.

Caney, Simon (2014) 'Justice and the basic right to justification’ in Forst, R Justice, Democracy and the Right to Justification: Rainer Forst in Dialogue. London: Bloomsbury.

Cavell, Stanley (1990) Conditions Handsome and Unhandsome: The Constitution of Emersonian Perfectionism. Chicago: University of Chicago Press.

Cooke, Maeve (2006) Re-presenting the Good Society. Cambridge MA: MIT Press.

Forst, Rainer (2015) 'A Critical Theory of politics: Grounds, methods and aims’ Philosophy and Social Criticism, 41 930, 225-34.

Forst, Rainer (2014a) ‘Noumenal Power’. The Journal of Political Philosophy, 1-17 
Forst, Rainer (2014b) Justice, Democracy and the Right to Justification: Rainer Forst in Dialogue. London: Bloomsbury.

Forst, Rainer, (2011) Justification and Critique: Toward a Critical Theory of Politics. Cambridge: Polity Press.

Forst, Rainer (2007) The Right to Justification: Elements of a Constructivist Theory of Justice. New York: Columbia University Press.

Forst, Rainer (1999) 'Justice, Reason and critique: basic concepts of critical theory' in Rasmussen, D (ed) The Handbook of Critical Theory. Oxford: Blackwells.

Fraser, N. (2008) 'Prioritizing Justice as Participatory Parity; A Reply to Kompridis and Forst' in Olson, K. (ed.) Adding Insult to Injury: Nancy Fraser debates her Critics. London: Verso.

Freyenhagen, Fabian (2013) Adorno’s Practical Philosophy: Living Less Wrongly. Cambridge: Cambridge University Press.

Fricker, Miranda (2009) Epistemic Injustice: Power and the Ethics of Knowing. Oxford: Oxford University Press.

Flynn, Jeffrey (2015) 'On the nature and status of the right to justification'. Political Theory, 43(6): 793-804.

Fritsch, Matthias (2015) 'Rational Justification and Vulnerability: On the "All-Affected” Principle in Rainer Forst’s Right to Justification’. Political Theory, 43(6): 805-21.

Hirschmann, Nancy (2002) The Subject of Liberty: Towards a Feminist Theory of Freedom. Princeton: Princeton University Press.

Honneth, Axel (2011) 'Rejoinder' in Danielle Petherbridge (ed) Axel Honneth: Critical Essays. Leiden: Brill. pp.391-421

Honneth, A. (2007) Disrespect: The Normative Foundations of Critical Theory. Cambridge: Polity Press.

Honneth, Axel (2004) 'A Social Pathology of Reason: On the intellectual legacy of Critical Theory’ in Rush, F. (ed.) The Cambridge Companion to Critical Theory. Cambridge: Cambridge University Press, 2004.

Jaggar, A (2014) (ed.) Gender and Global Justice. Cambridge: Polity Press.

McCarthy, Thomas (2009) Race, Empire and the Idea of Human Development. Cambridge: Cambridge University Press.

Medearis, J. (2004) 'Social Movements and Deliberative Democratic Theory’. British Journal of Political Science 35, pp. 53-75. 
Medina, Jose (2012) The Epistemology of Resistance: Gender and Racial Oppression, Epistemic Injustice and Resistant Imaginations. Oxford: Oxford University Press.

Mills, Charles (1998) Blackness Visible: Essays on Philosophy and Race .Cornell University Press.

Muller, Fernando Suarez (2013) 'Justifying the Right to Justification: An analysis of Rainer Forst’s constructivist theory of justice’. Philosophy and Social Criticism 39(10): 1049-68.

Okin, Susan (1989) Justice, Gender and the Family. New York: Basic Books.

Ranciere, Jacques (1999) Disagreement: Politics and Philosophy. Minneapolis: University of Minnesota Press.

Shklar, Judith (1990) The Faces of Injustice. Yale University Press.

Stears, M. (2010) Demanding Democracy: American Radicals in Search of a New Politics. Oxford: Princeton University Press.

Swift, Adam, White, Stuart (2008) 'Political Theory, Social Science, and real politics' in Leopold, D and Stears, M. Political Theory: Methods and Approaches. Oxford: Oxford University Press.

Tully, James (2011) ‘Dialogue’. Political Theory 39 (1): 145-60.

Walzer, Michael (1987) Interpretation and Social Criticism. Harvard University Press.

Young, Iris Marion (2009) 'The Gendered Cycle of Vulnerability in the Less Developed World' in eds Debra Satz and Rob Reich Toward a Humanist Justice: The Political Philosophy of Susan Moller Okin. Oxford: Oxford University Press, 2009. pp. 223-37. 